\title{
Quality of life in borderline patients comorbid with anxiety spectrum disorders - a cross- sectional study
}

\author{
Ales Grambal' \\ Jan Prasko' \\ Dana Kamaradova' \\ Klara Latalova' \\ Michaela Holubova ${ }^{1,2}$ \\ Zuzana Sedláčková ${ }^{3}$ \\ Radovan Hruby ${ }^{4}$ \\ 'Department of Psychiatry, Faculty \\ of Medicine and Dentistry, Palacky \\ University Olomouc, University \\ Hospital, Olomouc, ${ }^{2}$ Department of \\ Psychiatry, Hospital Liberec, Liberec, \\ ${ }^{3}$ Department of Psychology, Faculty \\ of Arts, Palacky University Olomouc, \\ Olomouc, Czech Republic; ${ }^{4}$ Private \\ Practice, Martin, Slovak Republic
}

This article was published in the following Dove Press journal:

Patient Preference and Adherence

I August 2016

Number of times this article has been viewed

Introduction: Borderline personality disorder (BPD) significantly reduces the quality of life (QoL) in mental, social, and work domains. Patients with BPD often suffer from depressive anxiety symptoms. The purpose of this cross-sectional study was to compare the QoL and demographic and clinical factors of inpatients diagnosed with BPD and comorbid anxiety spectrum disorders, and healthy controls.

Methods: Ninety-two hospitalized patients treated in the psychotherapeutic department and 40 healthy controls were included. Subjects were assessed by the Quality of Life Satisfaction and Enjoyment Questionnaire (Q-LES-Q), Dissociative Experiences Scale, Beck Depression Inventory (BDI)-II, Beck Anxiety Inventory, Clinical Global Impression, demographic questionnaire, Sheehan Disability Scale (SDS), and Sheehan Anxiety Scale.

Results: BPD patients suffered from comorbid anxiety disorders, panic disorder (18.5\%), social phobia (20.7\%), generalized anxiety disorder/mixed anxiety depression disorder (17.4\%), adjustment disorder (22.8\%), and posttraumatic stress disorder (8.7\%); 19.6\% patients had two or more anxiety disorder comorbidities. Patients score in Q-LES-Q (general) was 36.24 \pm 9.21 , which was significantly lower in comparison to controls $(57.83 \pm 10.21)$ and similar in all domains (physical health, feelings, work, household, school/study, leisure, social activities). The subjective level of depression measured by BDI and SDS (social life and family subscales) negatively correlated with all Q-LES-Q domains.

Conclusion: Patients suffering from BPD and comorbid anxiety disorders have a lower level of QoL compared to healthy controls in all measured domains. Negative correlations of the Q-LES-Q domains with clinical scales (Dissociative Experiences Scale, BDI, Beck Anxiety Inventory, Sheehan Anxiety Scale, Clinical Global Impression, and SDS) are noticeable.

Keywords: quality of life, borderline personality disorder, anxiety disorders, adjustment disorders, dissociation

\section{Introduction}

Patients with borderline personality disorder (BPD) suffer from difficulties in emotion regulation which include affective instability, impulsivity, fear of abandonment, eruptions of rage, feelings of emptiness, unstable interpersonal relationships, chronic dysphoria or depression, as well as heightened risk-taking behaviors. ${ }^{1-3}$ These emotional disturbances occur in association with negative thoughts about oneself and interpersonal poor functioning., 3 The impairment resulting from this condition and suicidal risk are mostly seen in the young-adult age and progressively decline with advancing age. ${ }^{3}$ The relationships of individuals with BPD may be chaotic, intense, and marked with difficulties. ${ }^{3,5}$ The prevalence of BPD in the general population,

Correspondence: Jan Prasko Department of Psychiatry, Faculty of Medicine and Dentistry, Palacky University Olomouc, University Hospital, IP Pavlova 6, 77520 Olomouc, Czech Republic

Tel +4206034l4930

Email praskojan@seznam.cz 
as shown by current community studies, is expected to be $0.5 \%-2.7 \%($ median $=0.7 \%) .{ }^{6,7}$ There are higher frequencies of BPD among patients in contact with mental health services, mainly inpatient departments, where up to one-fifth of patients may suffer from this disorder. ${ }^{8}$ People meeting diagnostic criteria for BPD pose a great challenge to therapists. They are frequently refractory, unpredictable, and become too close or too distant in the therapeutic relationship. ${ }^{9}$ They display high affective instability, are prone toward impulsive, self-mutilating, aggressive, and suicidal behavior, unstable identity, dissociation, conflicting interpersonal relations, chaotic lifestyle, high comorbidity levels, and low treatment efficacy. ${ }^{10-12}$ They provoke robust countertransferences in the therapist, who may become too rejecting or too seductive, or probably could fluctuate more among the extremes. ${ }^{6,13-15}$ Treatment possibilities include pharmacotherapy (especially mood stabilizers, atypical antipsychotics, or antidepressants) and psychotherapeutic interventions that are focused on affective dysregulation, increasing distress tolerance, changing distorted schemas and beliefs, and introducing new communication, and social and relationship problemsolving skills, especially in Dialectical Behaviour Therapy, Cognitive Therapy, and Schema Therapy or through intensive work with transference or mentalization in psychodynamic approaches like Transference Focus Therapy or Mentalization Therapy. ${ }^{14,16-21}$

Recently, as a result of an augmented focus on patients' experiences and their needs, the idea of the quality of life (QoL) has been taken into account in the investigation of psychiatric conditions, such as BPD. ${ }^{22}$ The dimension of the QoL gives additional information that supports a multidimensional view in research and treatment of BPD. ${ }^{22}$ QoL is gaining more significance as an important instrument to measure outcome of treatment interventions. Research data has established that QoL is strictly reduced in BPD. ${ }^{22,23}$ The fundamental problems of BPD include dissatisfaction, negative schemas about the person and others, and instability, which can significantly change some answers in a short time frame. BPD strongly impairs QoL across psychic, social, and physical domains. ${ }^{22}$ In a study by Perseius et $\mathrm{al}^{24}$ which compared the QoL between females with BPD and normal population, the authors found that women with BPD were significantly impaired in all areas, including emotional, cognitive, physical, and sexual functioning. Relations with their family and partner were also found to be impaired. Two studies have shown that the burden of BPD on individuals with different personality disorders is severe, and their QoL is manifestly impaired..$^{25,26}$ Nevertheless, the studies focused only on particular groups of patients, that is, people with the borderline disorder who do not function well. They did not capture satisfied or well-functioning individuals, and may reinforce the conclusion that people who have $\mathrm{BPD}$ also have reduced QoL. Following our studies of the QoL and related factors in schizophrenia ${ }^{27-29}$ and bipolar disorder, ${ }^{30}$ and on the basis of the outcomes in the literature, ${ }^{22}$ we decided to study the factors, which proved to be related to the QoL, like the severity of anxiety and depression, the degree of dissociation, unemployment, partner or marital problems, and the early onset of psychopathology.

One of the most important factors which could impair the QoL is functional impairment. Persons diagnosed with BPD are predisposed to have a substantial degree of functional impairment through a variety of social and occupational domains, including trouble with finding and maintaining adequate work, housing, or relations. ${ }^{31}$ BPD patients have poor social functioning; they are often socially isolated and unemployed or on long-term sick dispensation. ${ }^{32}$ Many patients with BPD do not finish their education or complete it at a minimal level. Similarly, many of them have a career which does not correspond with their capabilities, or they have no job at all. BPD patients often participate in problematic relationships and practice problematic parenting. ${ }^{3,33-35}$

Other factors which could influence the QoL in BPD are the severity of psychopathology and frequent comorbidities with other psychiatric disorders. ${ }^{22}$ The severity of the disorder is often increased in the case of comorbidities. ${ }^{12,36}$ Depression, anxiety, self-injury, suicide attempts, and substance abuse are frequent problems in BPD. ${ }^{37-39}$ People with BPD are associated with higher rates of deliberate self-harm and a high rate of completed suicide which is 50 times more than in the general population; $~ 8 \%-10 \%$ of BPD patients finish their lives prematurely due to suicide. ${ }^{33}$ Several studies have found that BPD patients are at heightened risk of developing depression and anxiety disorder, as well as frequent multiple comorbidities. ${ }^{12,39-44}$ In a US study on BPD, the results robustly predicted the persistence of four anxiety disorders (generalized anxiety disorder (GAD), social and specific phobias, and panic disorder) over 3 years. ${ }^{32}$ BPD negatively affects the course of social phobia, GAD, and posttraumatic stress disorder (PTSD). ${ }^{43,45}$ Dissimilarly, the anxiety disorders, aside from PTSD, have a minimal effect on BPD course. ${ }^{43}$

Job environment can be one of the areas where patients with BPD struggle for maintaining their identity. ${ }^{46-49}$ Conflicts with boss and colleagues are frequent; individuals with BPD mostly fight against assumed injustice and 
nepotism and accuse the others of incompetence, lack of diligence, and gaining benefits from their bosses. Occupational patterns are characterized by instability, intense preoccupation, the subsequent loss of interest in the job, lack of job satisfaction, and problems in relationships. ${ }^{48,49}$ Later in life, most of them achieve greater stability in social and work functioning. ${ }^{47}$

Numerous investigations established the close link between BPD and dissociation. ${ }^{50-53}$ Chronic and complex dissociative symptoms are common..$^{51,52,54-56}$ Dissociation is understood as a coping strategy to deal with tough, stressful circumstances, and with hurtful trauma experiences. ${ }^{54,57,58}$ Dissociative processes are usually recognized as the consequence of childhood trauma, although there are reports that genetic impacts are also significant. ${ }^{59}$ These processes result in the compartmentalization of thoughts, sensations, emotions, and memories that are too overwhelming for patients' consciousness to integrate. These processes may be maladaptive because it leads to an inaccurate understanding of reality, memory deficits, emotional freezing, feelings of disconnectedness with reality, and out-of-body experiences. Perhaps, these processes could explain the association between dissociation and many disorders including BPD. 3,50,51,60-62 Rather than this explanation, the vast majority of studies have focused on environmental antecedents of dissociative dispositions, notably childhood trauma. It has been fairly well established that exposure to childhood abuse facilitates the development of dissociative defense mechanisms. ${ }^{57,63}$ Childhood trauma has been connected with dissociation, and people exposed to childhood abuse display a greater degree of anxiety. ${ }^{64-66}$ There is a lack of studies about the QoL and dissociation in $\mathrm{BPD}$, but according to our previous study, a higher level of dissociation could be linked to the lower level of the QoL in bipolar disorder patients. ${ }^{10}$ Also, a review by Jones et $a l^{67}$ in adults with psychogenic nonepileptic seizures showed the association between health-related QoL and dissociation.

The aim of this study is to examine the QoL of borderline patients comorbid with anxiety spectrum disorders and compare this with the QoL of healthy controls. The second aim was to study if dissociation and demographic or clinical characteristics of the patients can influence QoL experienced by this population.

\section{Methods}

Consecutively hospitalized BPD patients with comorbid anxiety disorder were included in the study. All patients were treated at the same psychotherapeutic department for 6 weeks. Diagnoses were assessed and confirmed by two
Table I Inclusion and exclusion criteria

\begin{tabular}{ll}
\hline Inclusion criteria & Exclusion criteria \\
\hline $\begin{array}{l}\text { Diagnosis of emotionally unstable } \\
\text { personality disorder - borderline }\end{array}$ & Acute decompensation of severe \\
type according to ICD-10 & \\
$\begin{array}{l}\text { Male or female aged between } \\
\text { I8 and 65 years }\end{array}$ & History of bipolar affective disorder \\
Completed informed consent & History of major depressive disorder \\
& History of schizophrenia \\
& Mental retardation \\
& Current suicidal behavior \\
\hline
\end{tabular}

Abbreviation: ICD-10, International Classification of Diseases, Tenth Revision.

licensed psychiatrists, independently. The International Classification of Diseases ${ }^{68}$ was used as a primary diagnostic tool. Table 1 presents the inclusion and exclusion criteria.

\section{Brief description of the assessment tools} The Quality of Life Satisfaction and Enjoyment

The Quality of Life Satisfaction and Enjoyment Questionnaire (Q-LES-Q) ${ }^{69}$ is a questionnaire with 93 questions, divided into eight domains, answered mainly using a fivepoint Likert-type scale. It is self-completed, possibly with the help of an investigator. It takes from 20 to 30 minutes to complete, according to the health status of the patient. Patients complete the areas like physical health, feelings, leisure, social relations, and a summary of the QoL experienced during the past week. Müllerova et $\mathrm{al}^{70}$ validated the Czech version of the Q-LES-Q. The analyses indicated the high internal consistency (Cronbach alpha $=0.8-0.9$ ) and proved the stability of answers over time (test-retest). The particular Q-LES-Q tests correlated highly $(P>0.01)$ with the Hamilton Depression Rating Scale, Clinical Global Impression (CGI), and both BDI and BAI questionnaires.

\section{Dissociative Experiences Scale}

The Dissociative Experiences Scale (DES) ${ }^{71,72}$ is a selfadministered 28-item inventory of psychological dissociation, where patients rate on a visual analog scale as to how frequently they experience the dissociative symptoms (in the percentage of time). The Czech version of the scale is equal to the original version regarding its test-retest reliability, validity, and factor structure. ${ }^{73}$ Pathological DES was assessed by a Dissociative Experiences Scale Taxon (DES-T) based on the items of DES numbers 3, 5, 7, 8, $12,13,22$, and $27 . .^{74,75}$ These items measure identity alteration, depersonalization, derealization, discontinuation of awareness, dissociative amnesia, and auditory hallucinations. Cronbach alpha of DES was excellent $(\alpha=0.96) .^{74,76}$ 
The Czech translation showed psychometric properties equal to the original version of the scale. ${ }^{77}$

\section{Beck Depression Inventory}

The Beck Depression Inventory (BDI)-II ${ }^{78}$ scale includes 21 items covering main depressive symptoms. The patient rates the severity of each perceived symptom experienced during the last week. Internal consistency of the scale is higher in psychiatric population $(\alpha=0.86)$ than in general population $(\alpha=0.81) .{ }^{79}$ The Czech version was validated and published by Preiss and Vacir; the Cronbach alpha reached $0.89 .{ }^{80}$

\section{Beck Anxiety Inventory}

The Beck Anxiety Inventory (BAI $)^{81}$ scale is based on 21 items - anxiety symptoms - rated on a four-point Likert scale. The patient indicates perceived symptoms and their severity during the last week. The Cronbach alpha for the Czech version of the scale is $0.92 .^{82}$

\section{Clinical Global Impression}

The CGI ${ }^{83}$ scale is used for global assessment of the severity of psychopathology. The first evaluation is performed by the patient's psychologist or psychiatrist using the objective form of the scale evaluating the severity of the disorder (objCGI-S). The patient also assesses himself/herself by the subjective version (subjCGI-S), which includes seven levels of severity of the psychopathology. The intra-class correlations lie in the interval $0.88-0.92 .{ }^{84}$

\section{Demographic questionnaire}

The demographic questionnaire contains basic information such as sex, age, education, employment of pension status, age of disease onset, number of hospitalizations, time since the last hospitalization, duration of attendance at the outpatient clinic, number of visited psychiatrists, current medication, and discontinuation of drugs in the past (recommended by a psychiatrist or arbitrarily).

\section{Sheehan Disability Scale}

The Sheehan Disability Scale (SDS $)^{85-87}$ is a patient-rated, analog measure of functional disability in work, social, and family life. The patient rates the extent to which these areas of life are impaired on a ten-point visual scale. ${ }^{88}$

\section{Sheehan Anxiety Scale}

The Sheehan Anxiety Scale (SAS) $)^{86,89,90}$ (Sheehan PatientRated Anxiety Scale) is a 35-question multiple-choice selfinventory used to measure the severity of anxious symptoms.

\section{Treatments}

The mean duration of the outpatient treatments before admission to the hospital was $7.83 \pm 7.20$ years. At the time of the beginning of hospitalization, 82 patients were treated with psychopharmacies using usual dosages of antidepressants, or mood stabilizers, or low dosages of antipsychotics. Average dosages of antidepressants according to paroxetine index were $39.68 \pm 23.31 \mathrm{mg}$ per day $(\mathrm{n}=71)$, antipsychotics according to risperidone index were $1.68 \pm 1.63(n=35) \mathrm{mg}$ per day, antiepileptics lamotrigine were $179.40 \pm 90.67 \mathrm{mg}$ per day $(\mathrm{n}=17)$ or valproate were $1,067.00 \pm 394.10 \mathrm{mg}$ per day $(\mathrm{n}=18)$, and anxiolytics according to diazepam index were $12.00 \pm 11.65 \mathrm{mg}$ per day $(n=28)$. Two patients also used lithium at an average dosage of $750.00 \pm 212.10 \mathrm{mg}$ per day. Ten patients were medication-free (10.9\%), 25 patients used monotherapy (27.2\%; 19 antidepressants, six antiepileptics), 20 patients two drugs $(21.8 \% ; 12$ patients combination of antidepressant and antipsychotic, five patients combination of antiepileptic and antidepressant, three patients combination of antidepressant and anxiolytic), 33 patients three or more psychotropic drugs $(35.9 \%)$, and six patients four or more drugs in combination (6.5\%). Sixty-two (67.4\%) patients had undergone formal psychotherapy on an outpatient basis before the admission to the hospital. The types of previous psychotherapy were wide (gestalt therapy, psychodynamic group psychotherapy, existential psychotherapy, and supportive psychotherapy), but no empirically supported programs for BPD were used.

\section{Statistical analysis and ethics approval}

The statistical programs Prism3 (GraphPad Software, Inc., La Jolla, CA, USA) and SPSS 17 (SPSS Inc., Chicago, IL, USA) were used for statistics. Demographic data and scores of the specific questionnaires were assessed using descriptive statistics. Means, medians, standard deviations, and distribution of data were defined. The Shapiro-Wilk $W$ test was used to determine the Gaussian distribution of the demographic and QoL variables. The Student's $t$-tests or the Mann-Whitney tests were used for comparison of the means. The relationships between individual categories were analyzed using correlation coefficients and linear regression. The Fisher test or chi-square test was used to verify the connection between alternative variables (sex, marital status, discontinuation of the medication). The interactions between variables with normal distribution were calculated using Pearson correlation, while Spearman rank correlation was used for variables with non-normal distribution. Backward stepwise regressions were applied to analyze the significance of the correlations of the particular factors. Backward elimination, which we used, 
involved starting with all variables which correlated with the particular domain and deleting the variable that developed the statistical power of the model the most, and repeating the procedure until no additional upgrading was possible. The 5\% level of statistical significance was considered to be acceptable for all statistical tests. The ethics committee of University Hospital Olomouc approved the study. The investigation was conducted following the guidelines of the latest version of the Declaration of Helsinki and standards of Good Clinical Practice. ${ }^{91}$ Signed informed consent was obtained from all patients.

\section{Results}

\section{Sample description}

There were 515 patients with anxiety spectrum disorder admitted during the period from January 2010 to December
2014 to the psychotherapeutic department. Of them, 114 (22.1\% of total) were diagnosed with BPD with comorbid anxiety spectrum disorder. Twenty-two of them (19.3\%) refused to collaborate in the study. There were data from 92 patients used in the study. Forty healthy controls were recruited through advertisement (Table 2).

\section{Comparison of QoL in BPD patients and healthy controls}

The groups of patients and controls did not differ in mean age and the level of education, but there was a significant difference in marital status and occupation (Table 2). The QoL was statistically significantly impaired in all domains (physical health, feelings, work, household, school, leisure time, social activities, and QoL in general) measured by Q-LES-Q in both patients and controls (Table 1).

Table 2 Demographic and clinical data of the patients and controls

\begin{tabular}{|c|c|c|c|}
\hline Variable & Patients $(\mathrm{n}=92)$ & Controls $(n=40)$ & Statistic \\
\hline Age (years) & $30.49 \pm 9.25$ & $28.88 \pm 9.68$ & Mann-Whitney test; $U=I, 669 ;$ ns \\
\hline $\operatorname{Sex}(M: F)$ & $24: 68$ & $12: 28$ & Fisher's exact test; ns \\
\hline Age of disease onset of the psychiatric treatment (years) & $22.69 \pm 11.13$ & & \\
\hline Lifetime duration of treatment (years) & $7.83 \pm 7.20$ & & \\
\hline Psychiatric heredity & $42(45.7 \%)$ & & \\
\hline Education & & & Chi-square; ns \\
\hline Elementary & 13 & 2 & \\
\hline Vocational training & 21 & 4 & \\
\hline Secondary school & 46 & 28 & \\
\hline University & 12 & 6 & \\
\hline Marital status & & & Chi-square; $P<0.0005$ \\
\hline Single & 64 & 24 & \\
\hline Married & 12 & 12 & \\
\hline Divorced & 15 & 4 & \\
\hline Widowed & 1 & 0 & \\
\hline objCGI severity & $4.34 \pm 1.07$ & & \\
\hline subjCGI severity & $4.19 \pm 1.27$ & & \\
\hline BAI & $26.41 \pm 11.12$ & $7.88 \pm 7.41$ & Unpaired $t$-test: $t=I|.09, d f=| 30 ; P<0.000 \mid$ \\
\hline BDI & $29.03 \pm 10.09$ & $6.03 \pm 5.07$ & Unpaired $t$-test: $t=I|.93, d f=| 30 ; P<0.000 \mid$ \\
\hline \multicolumn{4}{|l|}{ Q-LES-Q domains } \\
\hline Physical health & $29.45 \pm 9.73(n=92)$ & $42.53 \pm I I .47(n=40)$ & Unpaired $t$-test: $t=6.7|4, d f=| 30 ; P<0.000 \mid$ \\
\hline Feelings & $30.48 \pm 9.61 \quad(n=69)$ & $44.70 \pm 5.91(n=30)$ & Unpaired $t$-test: $t=7.498, d f=97 ; P<0.0001$ \\
\hline Work & $42.22 \pm 10.88(n=32)$ & $55.12 \pm 6.72(n=17)$ & Unpaired $t$-test: $t=4.446, d f=47 ; P<0.0001$ \\
\hline Household & $33.8 \pm 8.75(n=92)$ & $55.18 \pm 8.43(n=40)$ & Unpaired $t$-test: $t=|3.04, d f=| 30 ; P<0.000 \mid$ \\
\hline School/study & $27.50 \pm 6.52(n=10)$ & $35.83 \pm 7.81(n=30)$ & Unpaired $t$-test: $t=3.032, d f=38 ; P<0.005$ \\
\hline Leisure & $17.15 \pm 4.95(n=92)$ & $25.03 \pm 3.96(n=40)$ & Unpaired $t$-test: $t=8.899, d f=|30 ; P<0.000|$ \\
\hline Social activities & $20.10 \pm 9.90(n=92)$ & $45.53 \pm 7.49(n=40)$ & Unpaired $t$-test: $t=8.809, d f=|30 ; P<0.000|$ \\
\hline General & $36.24 \pm 9.21(n=92)$ & $57.83 \pm 10.21(n=40)$ & Unpaired $t$-test: $t=|| .97, d f=|30 ; P<0.000|$ \\
\hline DES & $19.06 \pm 15.23$ & & \\
\hline DES-T & $13.55 \pm 17.38$ & & \\
\hline
\end{tabular}

Note: Data are presented as mean \pm SD or $n(\%)$.

Abbreviations: ns, non-significant; M, male; F, female; objCGI, objective Clinical Global Impression; subjCGI, subjective Clinical Global Impression; BAI, Beck Anxiety Inventory; BDI, Beck Depression Inventory; Q-LES-Q, Quality of Life Satisfaction and Enjoyment Questionnaire; df, degrees of freedom; DES, Dissociative Experiences Scale; DES-T, Dissociative Experiences Scale Taxon; SD, standard deviation. 
Table 3 Comorbid disorders with borderline personality disorder on Axis I and II

\begin{tabular}{lll}
\hline Types of comorbidity & $\begin{array}{l}\text { Number } \\
\text { of patients }\end{array}$ & $\begin{array}{l}\text { Percentage of } \\
\text { patients }\end{array}$ \\
\hline Anxiety spectrum disorders & & \\
$\quad$ Panic disorder/agoraphobia & 17 & 18.5 \\
Social phobia & 19 & 20.7 \\
Generalized anxiety disorder/ & 16 & 17.4 \\
mixed anxiety depression disorder & & \\
Obsessive-compulsive disorder & 5 & 5.4 \\
Posttraumatic stress disorder & 8 & 8.7 \\
Adjustment disorder & 21 & 22.8 \\
Somatoform disorder/dissociative & 6 & 6.5 \\
$\quad$ disorders & & \\
Two or more comorbidities & 18 & 19.6 \\
Axis Il comorbidities & & \\
Avoidant personality disorder & 6 & 6.5 \\
Mixed personality disorder & 6 & 6.5 \\
History of minor depressive & 5 & 5.4 \\
disorder & & \\
\hline
\end{tabular}

Note: Data are presented as $\mathrm{n}$ and $\%$.

\section{Comorbidity}

BPD comorbidity with other anxiety disorders on Axis I (according to the International Classification of Diseases, Tenth Revision) was identified. The percentage of comorbidities is presented in Table 3 .

Comparisons of the subgroups of patients with four different comorbid anxiety disorders (panic disorder/agoraphobia, social phobia, GAD, and adjustment disorder) were used for domains of physical health, feelings, household, leisure, social activities, and general, because there were enough responders, but not for domains of work and school/study, because there were not enough responders in the group of patients. Obsessive-compulsive disorder, PTSD, and somatoform disorder/dissociative disorder were collected in one subgroup named "others". The diagnostic subgroups did not statistically significantly differ in any of calculated Q-LES-Q domains (Table 4).

There were no statistically significant differences in the level of dissociation (DES) or pathological dissociation (DES-T) between comorbid diagnostic subgroups. There were no statistically significant differences in the degree of depression (BDI) and the level of general anxiety (BAI) between comorbid diagnostic subgroups, except the difference between comorbid panic disorder/agoraphobia and social phobia in BAI (Bonferroni's multiple comparison test). No statistically significant differences were seen between diagnostic comorbidity subgroups in anxiety symptoms measured by SAS, and global clinical severity measured by a physician using objCGI-S and by patients using subjCGI-S (Table 5). The comorbidity subgroups did not statistically differ in disabilities in work/school area (SDS-work/school), social life (SDS-social life), and family life (SDS-family).

\section{Relationship between the QoL in BPD and demographic and clinical variables}

The overall QoL negatively correlated highly with the severity of the disorder at the start of treatment, measured by CGI, by both psychiatrist and patient.

There was also a significant negative correlation between the overall QoL and level of anxiety measured by BAI and level of depression measured by BDI.

The domains of Q-LES-Q did not correlate significantly with age, length of the disorder, and age of the disorder onset except the negative correlation between the physical health domain of Q-LES-Q and age of the disorder onset

Table 4 Quality of life and comorbid diagnosis with different anxiety spectrum disorders

\begin{tabular}{|c|c|c|c|c|c|}
\hline $\begin{array}{l}\text { Q-LES-Q } \\
\text { domains }\end{array}$ & $\begin{array}{l}\text { Panic disorder/ } \\
\text { agoraphobia }(n=\mid 7)\end{array}$ & $\begin{array}{l}\text { Social phobia } \\
(n=19)\end{array}$ & $\begin{array}{l}\text { GAD } \\
(n=16)\end{array}$ & $\begin{array}{l}\text { Adjustment } \\
\text { disorders }(n=2 I)\end{array}$ & $\begin{array}{l}\text { Others } \\
(n=19)\end{array}$ \\
\hline Physical health & $26.9 \pm 8.5$ & $29.9 \pm 11.4$ & $29.6 \pm 6.5$ & $30.7 \pm 9.8$ & $29.7 \pm 11.7$ \\
\hline Statistic & \multicolumn{5}{|c|}{ One-way analysis of variance: $F=0.3693, d f=91$; ns } \\
\hline Feelings & $33.3 \pm 7.5$ & $28.6 \pm 11.4$ & $35.9 \pm 10.5$ & $29.4 \pm 9.5$ & $26.5 \pm 7.5$ \\
\hline Statistic & \multicolumn{5}{|c|}{ One-way analysis of variance: $F=2.183, d f=68$; ns } \\
\hline Household & $34.8 \pm 10.3$ & $32.4 \pm 8.4$ & $36.3 \pm 8.1$ & $34.8 \pm 7.3$ & $31.2 \pm 9.5$ \\
\hline Statistic & \multicolumn{5}{|c|}{ One-way analysis of variance: $F=1.013, d f=91$; ns } \\
\hline Leisure & $18.2 \pm 5.0$ & $16.4 \pm 5.2$ & $19.7 \pm 3.7$ & $16.5 \pm 4.9$ & $15.6 \pm 5 . \mid$ \\
\hline Statistic & \multicolumn{5}{|c|}{ One-way analysis of variance: $F=1.982, d f=91$; ns } \\
\hline Social activities & $31.9 \pm 14.6$ & $27.6 \pm 8.8$ & $30.8 \pm 8.5$ & $30.5 \pm 7.3$ & $29.9 \pm 10.0$ \\
\hline Statistic & \multicolumn{5}{|c|}{ One-way analysis of variance: $F=0.4596, d f=91$; ns } \\
\hline General & $35.2 \pm 9.1$ & $37.4 \pm 10.7$ & $36.5 \pm 10.1$ & $37.0 \pm 7.4$ & $35.0 \pm 9.5$ \\
\hline Statistic & \multicolumn{5}{|c|}{ One-way analysis of variance: $F=0.2446, d f=91 ; n s$} \\
\hline
\end{tabular}

Note: Data are presented as mean \pm SD.

Abbreviations: Q-LES-Q, Quality of Life Satisfaction and Enjoyment Questionnaire; GAD, generalized anxiety disorder; df, degrees of freedom; ns, nonsignificant; SD, standard deviation. 
Table 5 Comorbidity and clinical measurements

\begin{tabular}{|c|c|c|c|c|c|}
\hline & $\begin{array}{l}\text { Panic disorderl } \\
\text { agoraphobia }(n=17)\end{array}$ & $\begin{array}{l}\text { Social phobia } \\
(\mathrm{n}=19)\end{array}$ & $\begin{array}{l}\text { GAD } \\
(n=16)\end{array}$ & $\begin{array}{l}\text { Adjustment } \\
\text { disorders }(n=2 I)\end{array}$ & $\begin{array}{l}\text { Others } \\
(n=19)\end{array}$ \\
\hline DES & $19.45 \pm 16.66$ & $|4.0| \pm|2.0|$ & $18.53 \pm 14.24$ & $19.65 \pm 14.82$ & $23.59 \pm 17.84$ \\
\hline Statistic & \multicolumn{5}{|c|}{ One-way analysis of variance: $F=0.9563, d f=90 ; n s$} \\
\hline DES-T & $15.60 \pm 18.78$ & $8.07 \pm 10.80$ & $10.04 \pm|3.8|$ & $12.56 \pm 13.42$ & $21.17 \pm 24.90$ \\
\hline Statistic & \multicolumn{5}{|c|}{ One-way analysis of variance: $F=1.675, d f=90 ; n s$} \\
\hline BDI & $27.06 \pm 9.01$ & $26.74 \pm 10.7 \mid$ & $29.38 \pm 9.19$ & $30.52 \pm 9.56$ & $31.16 \pm 11.79$ \\
\hline Statistic & \multicolumn{5}{|c|}{ One-way analysis of variance: $F=0.5738, d f=91 ; n s$} \\
\hline BAI & $32.82 \pm|2.5|$ & $22.42 \pm 8.19$ & $24.75 \pm 10.69$ & $25.00 \pm 10.71$ & $27.63 \pm 11.59$ \\
\hline Statistic & \multicolumn{5}{|c|}{$\begin{array}{l}\text { One-way analysis of variance: } F=2.394, d f=91 \text {; ns }(P=0.0566) \text {; Bonferroni's multiple comparison test: } \\
\text { panic disorder/agoraphobia vs social phobia, } P<0.05\end{array}$} \\
\hline SAS & $71.06 \pm 19.82$ & $58.89 \pm 21.53$ & $58.38 \pm 20.29$ & $58.30 \pm 18.44$ & $64.68 \pm 25.75$ \\
\hline Statistic & \multicolumn{5}{|c|}{ One-way analysis of variance: $F=1.205, d f=90 ; n s$} \\
\hline objCGI-S & $4.77 \pm 0.90$ & $4.05 \pm 1.27$ & $4.19 \pm 1.05$ & $4.19 \pm 0.93$ & $4.53 \pm 1.12$ \\
\hline Statistic & \multicolumn{5}{|c|}{ One-way analysis of variance: $F=1.356, d f=91$; ns } \\
\hline subjCGI-S & $4.4 I \pm I .06$ & $4.42 \pm 1.12$ & $4.13 \pm 1.15$ & $3.76 \pm 1.48$ & $4.42 \pm 1.31$ \\
\hline Statistic & \multicolumn{5}{|c|}{ One-way analysis of variance: $F=1.082, d f=91$; ns } \\
\hline SDS-work/school & $6.80 \pm 2.66$ & $7.54 \pm 1.61$ & $6.55 \pm 2.81$ & $5.57 \pm 2.62$ & $6.8 I \pm 3.04$ \\
\hline Statistic & \multicolumn{5}{|c|}{ One-way analysis of variance: $F=1.003, d f=63 ; n s$} \\
\hline SDS-social life & $6.65 \pm 1.54$ & $7.26 \pm 2.28$ & $6.13 \pm 1.82$ & $6.00 \pm 2.56$ & $6.42 \pm 3.01$ \\
\hline Statistic & \multicolumn{5}{|c|}{ One-way analysis of variance: $F=0.8637, d f=90 ; n s$} \\
\hline SDS-family & $5.88 \pm 2.09$ & $5.68 \pm 2.36$ & $5.19 \pm 3.02$ & $5.55 \pm 2.59$ & $7.05 \pm 2.84$ \\
\hline Statistic & \multicolumn{5}{|c|}{ One-way analysis of variance: $F=1.365, d f=90 ; n s$} \\
\hline
\end{tabular}

Note: Data are presented as mean \pm SD.

Abbreviations: GAD, generalized anxiety disorder; DES, Dissociative Experiences Scale; DES-T, Dissociative Experiences Scale Taxon; BDI, Beck Depression Inventory; BAI, Beck Anxiety Inventory; SAS, Sheehan Anxiety Scale; objCGI, objective Clinical Global Impression; subjCGI, subjective Clinical Global Impression; SDS, Sheehan Disability Scale; df, degrees of freedom; ns, nonsignificant; SD, standard deviation.

(Table 6). From the psychopathological measures, the level of dissociation measured by DES and DES-T statistically negatively correlated with the domain leisure time; for example, the higher level of dissociation was linked to the lower level of QoL in leisure time. The subjective level of depression measured by BDI correlated with all Q-LES-Q domains. It was different for scales that measured anxiety level (BAI and SAS), since both significantly negatively correlated with domains of physical health, household, leisure time, and QoL in general but not with feelings, work, and

Table 6 Correlations of the Q-LES-Q results with demographic and clinical data

\begin{tabular}{|c|c|c|c|c|c|c|c|}
\hline Variable & Physical health & Feelings & Work & Household & Leisure & Social activities & General \\
\hline Age & $-0.1553^{a}$ & $0.2148^{\mathrm{a}}$ & $0.1342^{\mathrm{a}}$ & $0.0846^{a}$ & $0.0137^{\mathrm{a}}$ & $-0.0885^{a}$ & $-0.0812^{\mathrm{a}}$ \\
\hline Age of disorder onset & $-0.2093^{\mathrm{a}, *}$ & $0.098^{\mathrm{a}}$ & $0.274 I^{\mathrm{a}}$ & $0.0689^{a}$ & $-0.012 I^{a}$ & $0.0014^{\mathrm{a}}$ & $-0.0152^{\mathrm{a}}$ \\
\hline Length of the disorder & $0.0947^{a}$ & $\left.0.137\right|^{a}$ & $-0.2497^{\mathrm{a}}$ & $-0.0238^{\mathrm{a}}$ & $0.0340^{\mathrm{a}}$ & $-0.1101^{a}$ & $-0.08 \mathrm{I} \mathrm{I}^{\mathrm{a}}$ \\
\hline DES & $-0.1110^{b}$ & $-0.1047^{b}$ & $-0.072 I^{b}$ & $-0.1287^{b}$ & $-0.2240^{\mathrm{b}, *}$ & $-0.044 I^{\mathrm{b}}$ & $-0.0803^{b}$ \\
\hline DES-T & $-0.1249^{b}$ & $-0.1883^{b}$ & $-0.1558^{b}$ & $-0.1549^{b}$ & $-0.2394^{\mathrm{b}, *}$ & $-0.1342^{b}$ & $-0.1928^{b}$ \\
\hline BDI & $-0.4166^{\mathrm{a}, * * *}$ & $-0.3779 \mathrm{a}, * *$ & $-0.5493^{\mathrm{a}, * *}$ & $-0.6680^{\mathrm{a}, * * *}$ & $-\left.0.472\right|^{\mathrm{a}, * * *}$ & $-0.52 \mid 4^{\mathrm{a}, * * *}$ & $-0.6336^{\mathrm{a}, * * *}$ \\
\hline $\mathrm{BAI}$ & $-0.3629^{a}, * * *$ & $-0.0403^{\mathrm{a}}$ & $0.0603^{a}$ & $-\left.0.295\right|^{\mathrm{a}, * *}$ & $-0.2085^{\mathrm{a}, *}$ & $0.0122^{\mathrm{a}}$ & $-0.3506^{\mathrm{a}, * * *}$ \\
\hline SAS & $-0.3935^{\mathrm{a}, * * *}$ & $-0.1719^{a}$ & $-0.225 \mathrm{I}^{\mathrm{a}}$ & $-0.4420^{\mathrm{a}, * * *}$ & $-0.3623^{\mathrm{a}, * * *}$ & $-0.1577^{\mathrm{a}}$ & $-0.4642^{\mathrm{a}, * * *}$ \\
\hline objCGI-S & $-0.4119^{\mathrm{b}, * * * *}$ & -0.1021 & -0.1458 & $-0.5725^{\mathrm{b}, * * *}$ & $-0.3927^{\mathrm{b}, * * *}$ & $-0.34 I 5^{\mathrm{b}, * * *}$ & $-0.5498^{\mathrm{b}, * * *}$ \\
\hline subjCGI-S & $-0.2920^{\mathrm{b}, * *}$ & -0.0665 & -0.0479 & $-0.2930^{\mathrm{b}, * *}$ & -0.1482 & $-0.2726^{\mathrm{b}, *}$ & $-0.3676^{\mathrm{b}, * * *}$ \\
\hline SDS-work & $-0.3547^{b, * * *}$ & $-0.058^{b}$ & $-0.2882^{b}$ & $-0.2357^{b}$ & $-0.238 I^{\mathrm{a}, *}$ & $-0.1636^{b}$ & $-0.1778^{b}$ \\
\hline SDS-social life & $-0.3437^{b, * * *}$ & $-0.360 \mathrm{I}^{\mathrm{b}, * *}$ & $-0.54 \mid 4^{b, * *}$ & $-0.5355^{b, * * *}$ & $-0.5257^{b, * * *}$ & $-0.5667^{b, * * *}$ & $-0.5506^{b, * * *}$ \\
\hline SDS-family & $-0.3715^{b, * * *}$ & $-0.3650^{\mathrm{b}, * *}$ & $-0.4659^{\mathrm{b}, * *}$ & $-0.5284^{\mathrm{b}, * * *}$ & $-0.5163^{\mathrm{b}, * * * *}$ & $-0.4798^{\mathrm{b}, * * *}$ & $-0.5519 \mathrm{~g}, * * *$ \\
\hline Antidepressants $(n=63)$ & $-0.1820^{\mathrm{a}}$ & $-0.0177^{a}$ & $-0.0818^{a}$ & $-0.210 \mathrm{I}^{\mathrm{a}}$ & $-0.2733^{\mathrm{a}, *}$ & $-0.2300^{\mathrm{a}}$ & $-0.2347^{a, *}$ \\
\hline Antipsychotics $(n=35)$ & $-0.2328^{a}$ & $-0.2694^{\mathrm{a}}$ & $0.1127^{a}$ & $-0.1288^{a}$ & $-0.3202^{\mathrm{a}}$ & $-0.2702^{\mathrm{a}}$ & $-0.2389^{a}$ \\
\hline Anxiolytics $(n=28)$ & 0.2289 & 0.2130 & $-0.0634^{\mathrm{a}}$ & $-0.2339^{a}$ & $-0.003 I^{a}$ & $-0.0166^{a}$ & $-0.2496^{a}$ \\
\hline
\end{tabular}

Notes: Data are presented as mean $\pm S D$. aPearson. bSpearman. $* P<0.05$. $* * P<0.01$. $* * * P<0.001$.

Abbreviations: Q-LES-Q, Quality of Life Satisfaction and Enjoyment Questionnaire; DES, Dissociative Experiences Scale; DES-T, Dissociative Experiences Scale Taxon; BDI, Beck Depression Inventory; BAI, Beck Anxiety Inventory; S, severity; SAS, Sheehan Anxiety Scale; objCGI, objective Clinical Global Impression; subjCGI, subjective Clinical Global Impression; SDS, Sheehan Disability Scale; SD, standard deviation. 
social activities domains. The same result was seen for the correlation of subjCGI-S (Table 6). ObjCGI-S did not statistically significantly correlate with two domains, feelings and work, but with all other domains, there were highly significant negative correlations; a higher level of global clinical severity was associated with the lower level of QoL in most of the domains. The subjective level of handicaps measured by SDS showed statistically negative correlation of subscale work with domains of physical health and leisure time, and the negative correlation of subscale social life and subscale family with all domains of Q-LES-Q (Table 6).

There were only two statistically significant negative correlations between Q-LES-Q domains and medication, both with a dosage of an antidepressant, which negatively correlated with leisure time and QoL in general. There was no significant correlation between dosages of antipsychotics and anxiolytics (Table 6).

\section{Regression analysis}

Because of the numerous aspects significantly related to the Q-LES-Q domains, a multiple regression analysis was performed (backward stepwise regression) to identify the most important factors connected with each domain of the Q-LES-Q in patients with BPD. The dependent variable was the domains of the Q-LES-Q questionnaire. Demographic variables and scores of the questionnaires were used as the independent variables, which correlated with each domain (Table 7).

In the physical health domain, backward stepwise regression contained five steps, and the initial nine parameters narrowed to four independent, of which three explained that this domain was statistically significant with a negative sign. These were the age of onset of the disorders, severity of depressive symptoms assessed by BDI, and the rate of disability at work in subscale SDS-work. This means that the lower age of onset of disorders, a lower level of depression, and lower subjective evaluation of disability in the working area are connected with the higher QoL in the domain of physical health (Table 7).

In the domain of feelings, backward stepwise regression reduced from three to two independent factors already in the second step. Only one was statistically significant with a negative sign; it was an assessment of the disability in family functioning (SDS-family). If the patients evaluated their

Table 7 Backward stepwise regression of the factors correlated with Q-LES-Q domains

\begin{tabular}{|c|c|c|c|c|c|c|c|}
\hline & \multicolumn{7}{|c|}{ Domain (dependent variables) } \\
\hline & $\begin{array}{l}\text { Physical } \\
\text { health }\end{array}$ & Feelings & Work & Household & Leisure & $\begin{array}{l}\text { Social } \\
\text { activities }\end{array}$ & General \\
\hline Significant correlation & Onset & $\mathrm{BDI}$ & $\mathrm{BDI}$ & $\mathrm{BDI}$ & DES & $\mathrm{BDI}$ & $\mathrm{BDI}$ \\
\hline with (independent & BAl & SDS-family & SDS-social & SDS-family & $\mathrm{BAl}$ & SDS-social & SDS-social \\
\hline \multirow[t]{7}{*}{ variables) } & $\mathrm{BDI}$ & SDS-social & SDS-family & SDS-social & $\mathrm{BDI}$ & SDS-family & SDS-family \\
\hline & SAS & & & BAl & SAS & & AD dosage \\
\hline & objCGI & & & SAS & objCGI & & \\
\hline & SDS-work & & & objCGI & SDS-work & & \\
\hline & SDS-social & & & & SDS-social & & \\
\hline & SDS-family & & & & SDS-family & & \\
\hline & & & & & $A D$ dosage & & \\
\hline Number of steps & 5 & 2 & 3 & 4 & 8 & 2 & 3 \\
\hline Adjusted $r^{2}$ & 0.301 & 0.227 & 0.267 & 0.533 & 0.495 & 0.340 & 0.510 \\
\hline \multirow[t]{12}{*}{ Variables } & Onset: & BDI: & BDI: & BDI: & DES: & SDS-social: & SDS-social: \\
\hline & $\beta=-0.256$ & $\beta=-0.226$ & $\beta=-0.539$, & $\beta=-0.493$ & $\beta=-0.230$ & $\beta=-0.322$ & $\beta=-0.429$, \\
\hline & $P=0.018^{*}$ & $P=0.056$ & $P=0.002 * *$ & $P=0.000 * * *$ & $P=0.033^{*}$ & $P=0.001 * * *$ & $P=0.000 * * *$ \\
\hline & BAI: & SDS-family: & & SDS-family: & SDS-social: & BDI: $\beta=-0.386$ & BDI: \\
\hline & $\beta=-0.200$ & $\beta=-0.368$ & & $\beta=-0.176$ & $\beta=-0.635$ & $P=0.000 * * *$ & $\beta=-0.395$, \\
\hline & $P=0.088$ & $P=0.002 * *$ & & $P=0.045^{*}$ & $P=0.000 * * *$ & & $P=0.000 * * *$ \\
\hline & BDI: & & & SDS-social: & & & \\
\hline & $\beta=-0.332$ & & & $\beta=-0.242$ & & & \\
\hline & $P=0.005^{* *}$ & & & $P=0.006$ ** & & & \\
\hline & SDS-work: & & & & & & \\
\hline & $\beta=-0.265$ & & & & & & \\
\hline & $P=0.015^{*}$ & & & & & & \\
\hline
\end{tabular}

Notes: $\beta$ is the standardized coefficient. $* P<0.0$ I; $* * P<0.01 ; * * * P<0.001$.

Abbreviations: Q-LES-Q, Quality of Life Satisfaction and Enjoyment Questionnaire; BDI, Beck Depression Inventory; DES, Dissociative Experiences Scale; BAI, Beck Anxiety Inventory; SDS, Sheehan Disability Scale; SAS, Sheehan Anxiety Scale; AD, antidepressant; objCGI, objective Clinical Global Impression. 
disability in family functioning as lower, they would assess their QoL in the domain of feelings as better.

In the domain of work, which was completed only by 32 participants (having a job), the backward stepwise regression dropped during third step to a single factor, which was BDI total score. The standardized $\beta$ coefficient was negative for this factor. This means that the patients who have fewer symptoms of depression also have the higher QoL in the domain of work.

The domain of household initially significantly correlated with a total of nine factors including the dose of antidepressant medication. During the three steps, three most important independent factors were taken: rates of depression, the rate of disability in the family, and the level of social impairment, which was significantly related to the functioning of the household domain. All the three factors had a negative standardized $\beta$ coefficient. This means that the lower the level of depression, disability in the family, and social impairment, the higher the QoL in the family.

The domain leisure correlated with ten clinical factors. During the eight steps, six factors gradually phased out, leaving only the rate of dissociation evaluated by DES and the assessment of the disability in social functioning, both with a negative sign in a standardized $\beta$ coefficient. This means that the lower the rate of dissociation and less perceived the handicap in social functioning, the higher the QoL in the domain of leisure.

The domain social activities correlated with three factors at the start. During the second step, two independent factors remained, which were significantly associated with this domain. They were the social adjustment and the degree of depression. Both factors had a negative sign of a standardized $\beta$ coefficient.

The domain of general correlated with the four factors at the start. After three steps of backward regression analysis, the factors were reduced to two independent factors. They were social disability and severity of depression; both had a negative sign of the standardized coefficient $\beta$. This means that the lower the severity of depression and social impairment, the higher the general subjective QoL (Table 7).

\section{Discussion}

In our study, patients and healthy controls were well matched for age, sex, and education, showing no significant distinctions. Differences in marital status were referred to previous papers. ${ }^{92}$ Also in our sample of patients, it was more common to be a single or divorced person compared to controls. As we expected, patients scored significantly more items in BAI and BDI than controls. High level of depression in BPD patients is frequent also in other studies, ${ }^{93}$ and the comorbidity with depressive disorders is also common. ${ }^{39,94}$ The higher level of anxiety measured by BAI is predictable in patients with comorbid anxiety disorders. The relatively high match between subjCGI and objCGI could be surprising in borderline patients, who often say that they are healthy and have not been really ill patients. The harmony between the objective and subjective evaluation of the severity of the disorder contrasts with the common stigmatizing belief of clinicians that patients with BPD are manipulative and aggravate their problems., ${ }^{9,95}$

The main aim of our study was to investigate the QoL in BPD comorbid with anxiety disorders and compare it with the QoL of healthy controls. BPD patients experienced statistically significantly impaired QoL compared with the healthy controls (Figure 1) in all measured domains of QoL (physical health, feelings, work, household, school, leisure time, and in general). These results are in agreement with the results of the other studies, where BPD strongly impairs the QoL in all areas. ${ }^{22,24,96}$ However, BPD patients included in our study were comorbid with anxiety disorders (Table 2). Because of this comorbidity, it is hard to say to what extent the personality disorder itself influences the reduced QoL and to what extent the anxiety disorder influences. It was demonstrated that anxiety disorders affect the QoL. ${ }^{97}$ The question remains as to what is the influence of anxiety disorders and what is the impact of personality disorder itself on reduced QoL in borderline patients. The concrete personal impact on the QoL could be different. ${ }^{43,96,97}$ Moreover, it is hard to measure the proportion of impact for each entity. In the Czech Republic, patients are usually hospitalized because

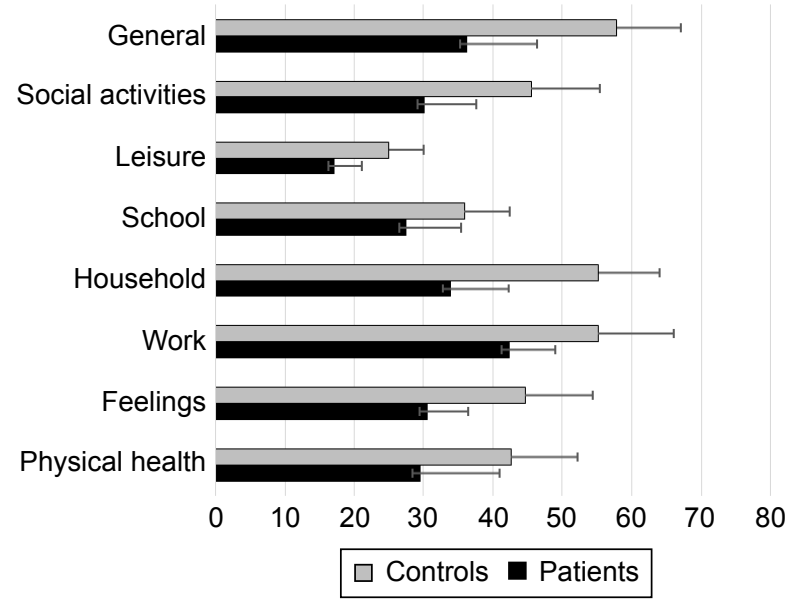

Figure I Q-LES-Q domains in controls and patients in percents. Abbreviation: Q-LES-Q, Quality of Life Satisfaction and Enjoyment Questionnaire. 
of their increased suicide risk or comorbid disorders but not for the BPD itself. However, the level of QoL and clinical variables in BPD patients were not influenced by the type of comorbid anxiety disorder (Tables 3 and 4). This may be related to the relatively low impact of anxiety disorders on QoL or correlated with the disability in work.

In line with expectations, when we look at the measurements of the intensity of psychopathology and its relationship with QoL, the overall QoL correlated with both subjCGI and objCGI, and with the level of depression measured by BDI. Whereas objCGI and SAS correlate with physical health, household, and leisure domains, the subjCGI correlates with physical health and household but not leisure domain. The level of depression exhibits the impact on all domains of Q-LES-Q. The severity of the disorder correlated with the QoL was also identified in other psychiatric diseases, like bipolar disorder and schizophrenia. ${ }^{28,98}$ Four domains out of seven correlated with the subjective level of anxiety. The difference may indicate a greater importance of the subjective perception of depressive symptoms than anxiety symptoms in the QoL in borderline patients. In contrast, another study ${ }^{99}$ showed anxiety and depressive symptoms to be identically associated with all domains of QoL in primary care patients.

Psychological dissociation assessed with the DES was not correlated with most domains of the QoL measured by Q-LES-Q, except the domain of leisure time (Table 5). In previous studies, the authors have described a reduced QoL due to dissociation and PTSD, in traumatized individuals ${ }^{100,101}$ and sexually abused women. ${ }^{102}$ Dissociation protects individuals against the negative emotions but also prevents experiencing positive emotions, which are of particular importance for leisure. The more the patients dissociate, the lower the level of quality of leisure time they experience.

The antidepressant dosage negatively correlated with leisure time and QoL in general. Antidepressant medication and dissociation correlate with the QoL in a remarkably similar manner. The emotional detachment was described by the patients using antidepressants as one of the common side effects. ${ }^{103}$ In other words, antidepressants may produce symptoms similar to dissociation and reduce the quality of leisure domain.

All domains of QoL statistically significantly correlated with social life and family life when assessed by SDS. This means that people, who assessed their social life and family life as more handicapped, experience impaired QoL in all domains. It is interesting that it is not visible in the assessment of disability in work, where only two domains, physical health and QoL in general, statistically significantly negative correlated with.

\section{Limitations of the study}

The present study had several limitations. The patients were mostly unemployed for a long time, which could influence the QoL in all domains. Also, the selection of difficult-totreat BPD patients can affect the outcome of the study: the patients referred to inpatient treatment were individuals who were difficult to treat with high levels of comorbidity with other psychiatric disorders. Additionally, the percentage of the explained variance in the different models was modest. Another limitation was that subjective self-rating questionnaires were mostly used, with unknown reliability in this population.

Therefore, it was difficult to assume that these results could be generalized to BPD patients as a group. Future surveys should examine groups that include the outpatient BPD patients with a lower frequency of comorbidity. The QoL in this study was measured by the Q-LES-Q, which is not a QoL questionnaire specific to BPD. On the other hand, when a study compares patients and healthy controls, it is necessary to use the instrument appropriate for both groups. Future research should verify these questionnaires with clinician-rated instruments.

An additional limitation of the study was the relatively small sample size. Patients, in comparison with the controls, were medicated, and possible side-effects could explain part of the differences seen between patients with BPD and controls.

\section{Conclusion}

BPD patients suffering from comorbid anxiety disorder have an impaired QoL compared to healthy controls in all measured domains (physical health, feelings, work, household, school, leisure time, and in general). Negative correlations of the Q-LES-Q domains with clinical scales (DES, BDI, BAI, SAS, CGI, and SDS) are noticeable. In future, longitudinal investigation is needed to focus on how psychopathological symptoms affect the subjective QoL and if the QoL could change during the therapy.

\section{Acknowledgment}

This paper was supported by the research grant IGA MZ ČR NS 9752-3/2008. 


\section{Disclosure}

The authors report no conflicts of interest in this work.

\section{References}

1. World Health Organisation. ICD-10 Classifications of Mental and Behavioural Disorder: Clinical Descriptions and Diagnostic Guidelines. Geneva: World Health Organisation; 1992.

2. Brüne M. Borderline personality disorder: why 'fast and furious'? Evol Med Public Health. 2016;2016(1):52-66.

3. American Psychiatric Association. Diagnostic and Statistical Manual of Mental Disorders. 5th ed. Arlington, VA: American Psychiatric Publishing; 2013.

4. American Psychiatric Association. Diagnostic and Statistical Manual of Mental Disorders. 4th ed. Washington DC: American Psychiatric Association; 1994

5. Arntz A, van Genderen H. Schema Therapy for Borderline Personality Disorder. Chichester: Wiley-Blackwell; 2009.

6. Coid J, Yang M, Tyrer P, Roberts A, Ullrich S. Prevalence and correlates of personality disorder in Great Britain. Br J Psychiatry. 2006;188(5) 423-431.

7. Samuels J. Personality disorders: epidemiology and public health issues. Int Rev Psychiatry. 2011;23(3):223-233.

8. Hayward M, Slade M, Moran PA. Personality disorders and unmet needs among psychiatric inpatients. Psychiatr Serv. 2006;57(4) 538-543.

9. Vyskocilova J, Prasko J, Sedlackova Z, Ociskova M, Grambal A. Schema therapy for CBT therapists who treat borderline patients. Act Nerv Super Rediviva. 2014;56(1-2):24-31.

10. Latalova K, Prasko J. Aggression in borderline personality disorder. Psychiatr Q. 2010;81:239-251.

11. Fornaro M, Orsolini L, Marini S, et al. The prevalence and predictors of bipolar and borderline personality disorders comorbidity: systematic review and meta-analysis. J Affect Disord. 2016;195:105-118.

12. Vyskocilova J, Prasko J, Novak T, Pohlova L. Is there any influence of personality disorder on the short term intensive group cognitive behavioral therapy of social phobia? Biomed Pap Med Fac Univ Palacky Olomouc Czech Repub. 2011;155(1):85-94.

13. American Psychiatric Association. Practice guideline for the treatment of patients with borderline personality disorder. Am J Psychiatry. 2001; 158(10 Suppl):1-52.

14. Davidson KM, Tyrer P, Norrie J, Palmer SJ, Tyrer H. Cognitive therapy v. usual treatment for borderline personality disorder: prospective 6-year follow-up. Br J Psychiatry. 2010;197(6):456-462.

15. Prasko J, Diveky T, Grambal A, et al. Transference and countertransference in cognitive behavioral therapy. Biomed Pap Med Fac Univ Palacky Olomouc Czech Repub. 2010;154(3):189-198.

16. Linehan MM, Kehrer CA. Borderline personality disorder. In: Barlow DH, editor. Clinical Handbook of Psychological Disorders. A Step-by-Step Treatment Manual. 2nd ed. New York, NY: Guilford; 1993:396-441.

17. Giesen-Bloo J, van Dyck R, Spinhoven P, et al. Outpatient psychotherapy for borderline personality disorder: randomized trial of schema-focused therapy vs transference-focused psychotherapy. Arch Gen Psychiatry. 2006;63(6):649-658.

18. Doering S, Hörz S, Rentrop M, et al. Transference-focused psychotherapy v. treatment by community psychotherapists for borderline personality disorder: randomised controlled trial. Br J Psychiatry. 2010; 196(5):389-395.

19. Fonagy P. The effectiveness of psychodynamic psychotherapies: an update. World Psychiatry. 2015;14(2):137-150.

20. Clarkin JF. An integrated approach to psychotherapy techniques for patients with personality disorder. J Pers Disord. 2012;26(1):43-62.

21. Reneses B, Galián M, Serrano R, et al. A new time limited psychotherapy for BPD: preliminary results of a randomized and controlled trial. Actas Esp Psiquiatr. 2013;41(3):139-148.
22. IsHak WW, Elbau I, Ismail A, et al. Quality of life in borderline personality disorder. Harv Rev Psychiatry. 2013;21(3):138-150.

23. Black DW, Blum N, Letuchy E, Doebbeling C, Forman-Hoffman VL, Doebbeling BN. Borderline personality disorder and traits in veterans: psychiatric comorbidity, healthcare utilization, and quality of life along a continuum of severity. CNS Spectr. 2006;11(9):680-689.

24. Perseius KI, Andersson E, Asberg M, Samuelsson M. Health-related quality of life in women patients with borderline personality disorder. Scand J Caring Sci. 2006;20(3):302-307.

25. Feenstra DJ, Hutsebaut J, Laurenssen EM, Verheul R, Busschbach JJ, Soeteman DI. The burden of disease among adolescents with personality pathology: quality of life and costs. J Pers Disord. 2012;26(4): 593-604.

26. Soeteman DI, Verheul R, Busschbach JJ. The burden of disease in personality disorders: diagnosis-specific quality of life. J Pers Disord. 2008;22(3):259-268.

27. Sidlova M, Prasko J, Jelenova D, et al. The quality of life of patients suffering from schizophrenia - a comparison with healthy controls. Biomed Pap Med Fac Univ Palacky Olomouc Czech Repub. 2011;155(2): 173-180.

28. Holubova M, Prasko J, Hruby R, et al. Coping strategies and quality of life in schizophrenia: cross-sectional study. Neuropsychiatr Dis Treat. 2015;11:3041-3048.

29. Holubova M, Prasko J, Latalova K, et al. Are self-stigma, quality of life, and clinical data interrelated in schizophrenia spectrum patients? A cross-sectional outpatient study. Patient Prefer Adherence. 2016;10: 265-274.

30. Latalova K, Prasko J, Diveky T, Kamaradova D, Velartova H. Cognitive dysfunction, dissociation and quality of life in bipolar affective disorders in remission. Psychiatr Danub. 2010;22(4):528-534.

31. Wilks CR, Korslund KE, Harned MS, Linehan MM. Dialectical behavior therapy and domains of functioning over two years. Behav Res Ther. 2016;77:162-169.

32. Skodol AE, Geier T, Grant BF, Hasin DS. Personality disorders and the persistence of anxiety disorders in a nationally representative sample. Depress Anxiety. 2014;31(9):721-728.

33. Lieb K, Zanarini MC, Schmahl C, Linehan MM, Bohus M. Borderline personality disorder. Lancet. 2004;364:453-461.

34. Lavner JA, Lamkin J, Miller JD. Borderline personality disorder symptoms and newlyweds' observed communication, partner characteristics, and longitudinal marital outcomes. J Abnorm Psychol. 2015;124(4): 975-981.

35. Petfield L, Startup H, Droscher H, Cartwright-Hatton S. Parenting in mothers with borderline personality disorder and impact on child outcomes. Evid Based Ment Health. 2015;18(3):67-75.

36. Prasko J, Houbova P, Novak T, et al. Influence of personality disorder on the treatment of panic disorder - comparison study. Neuro Endocrinol Lett. 2005;26(6):667-674.

37. Harned MS, Tkachuck MA, Youngberg KA. Treatment preference among suicidal and self-injuring women with borderline personality disorder and PTSD. J Clin Psychol. 2013;69(7):749-761.

38. Williams GE, Daros AR, Graves B, McMain SF, Links PS, Ruocco AC. Executive functions and social cognition in highly lethal self-injuring patients with borderline personality disorder. Personal Disord. 2015; 6(2):107-116

39. Köhling J, Moessner M, Ehrenthal JC, et al. Affective instability and reactivity in depressed patients with and without borderline pathology. J Pers Disord. Epub 2015 Dec 1.

40. Alnaes R, Torgersen S. The relationship between DSM-III symptom disorders (Axis I) and personality disorders (Axis II) in an outpatient population. Acta Psychiatr Scand. 1988;78(4):485-492.

41. Oldham JM, Skodol AE, Kellman HD, et al. Comorbidity of axis I and axis II disorders. Am J Psychiatry. 1995;152(4):571-578.

42. Zanarini MC, Frankenburg FR, Dubo ED, et al. Axis I comorbidity of borderline personality disorder. Am J Psychiatry. 1998;155(12): $1733-1739$. 
43. Keuroghlian AS, Gunderson JG, Pagano ME, et al. Interactions of borderline personality disorder and anxiety disorders over 10 years. J Clin Psychiatry. 2015;76(11):1529-1534.

44. Baryshnikov I, Suvisaari J, Aaltonen K, et al. Self-reported symptoms of schizotypal and borderline personality disorder in patients with mood disorders. Eur Psychiatry. 2016;33:37-44.

45. Ansell EB, Pinto A, Edelen MO, et al. The association of personality disorders with the prospective 7-year course of anxiety disorders. Psychol Med. 2011;41(5):1019-1028.

46. Janosiková EH, Daviesová JL. Psychiatrická ošetrovatel ská starostlivost' (Preklad z amerického originálu) [Psychiatric Nursing (Translation from the American Original)]. Martin: Vydavatel'stvo Osveta; 1999. Slovak.

47. Zanarini MC, Frankenburg FR, Hennen J, Silk KR. The longitudinal course of borderline psychopathology: 6-year prospective follow-up of the phenomenology of borderline personality disorder. Am J Psychiatry. 2003;160(2):274-283.

48. Bagge C, Nickell A, Stepp S, Durrett C, Jackson K, Trull TJ. Borderline personality disorder features predict negative outcomes 2 years later. J Abnorm Psychol. 2004;113(2):279-288.

49. Larivière N, Couture É, Blackburn C, et al. Recovery, as experienced by women with borderline personality disorder. Psychiatr Q. 2015;86(4): 555-568.

50. Zanarini MC, Ruser T, Frankenburg FR, Hennen J. The dissociative experiences of borderline patients. Compr Psychiatry. 2000;41(3): 223-227.

51. Pastucha P, Prasko J, Diveky T, et al. Borderline personality disorder and dissociation - comparison with healthy controls. Act Nerv Super Rediviva. 2009;51(3-4):146-149.

52. Paris J, Zweig-Frank H. Dissociation in patients with borderline personality disorder. Am J Psychiatry. 1997;154(1):137-138.

53. Spitzer C, Barnow S, Armbruster J, Kusserow S, Freyberger HJ, Grabe HJ. Borderline personality organization and dissociation. Bull Menninger Clin. 2006;70(3):210-221.

54. Ross CA. Borderline personality disorder and dissociation. J Trauma Dissociation. 2007;8(1):71-80.

55. Navarro-Haro MV, Wessman I, Botella C, García-Palacios A. The role of emotion regulation strategies and dissociation in non-suicidal selfinjury for women with borderline personality disorder and comorbid eating disorder. Compr Psychiatry. 2015;63:123-130.

56. Niedtfeld I, Defiebre N, Regenbogen C, et al. Facing the problem: impaired emotion recognition during multimodal social information processing in borderline personality disorder. J Pers Disord. Epub 2016 Apr 11.

57. Simeon D, Guralnik O, Schmeidler J, Sirof B, Knutelska M. The role of childhood interpersonal trauma in depersonalization disorder. $\mathrm{Am} \mathrm{J}$ Psychiatry. 2001;158(7):1027-1033.

58. Watson S, Chilton R, Fairchild H, Whewell P. Association between childhood trauma and dissociation among patients with borderline personality disorder. Aust N Z J Psychiatry. 2006;40(5):478-481.

59. Savitz JB, van der Merwe L, Newman TK, Solms M, Stein DJ, Ramesar RS. The relationship between childhood abuse and dissociation. Is it influenced by catechol-O-methyltransferase (COMT) activity? Int J Neuropsychopharmacol. 2008;11(2):149-161.

60. Prasko J, Raszka M, Diveky T, et al. Obsessive-compulsive disorder and dissociation - comparison with healthy controls. Biomed Pap Med Fac Univ Palacky Olomouc Czech Repub. 2010;154(2):179-183.

61. Prasko J, Latalova K, Diveky T, et al. Panic disorder, autonomic nervous system and dissociation - changes during therapy. Neuro Endocrinol Lett. 2011;32(5):641-651.

62. Latalova K, Prasko J, Pastucha P, et al. Bipolar affective disorder and dissociation - comparison with healthy controls. Biomed Pap Med Fac Univ Palacky Olomouc Czech Repub. 2011;155(2):181-186.

63. Draijer N, Langeland W. Childhood trauma and perceived parental dysfunction in the etiology of dissociative symptoms in psychiatric inpatients. Am J Psychiatry. 1999;156:379-385.
64. Roy A. Childhood trauma and neuroticism as an adult: possible implication for the development of the common psychiatric disorders and suicidal behavior. Psychol Med. 2002;32:1471-1474.

65. McFarlane A, Clark CR, Bryant RA, et al. The impact of early life stress on psychophysiological, personality and behavioral measures in 740 non-clinical subjects. J Integr Neurosci. 2005;4:27-40.

66. Stein MB, Schork NJ, Gelernter J. Gene-by-environment (serotonin transporter and childhood maltreatment) interaction for anxiety sensitivity, an intermediate phenotype for anxiety disorders. Neuropsychopharmacology. 2008;33(2):312-319.

67. Jones B, Reuber M, Norman P. Correlates of health-related quality of life in adults with psychogenic nonepileptic seizures: a systematic review. Epilepsia. 2016;57(2):171-181.

68. Mezinárodni klasifikace nemoci - 10. revize, MKN-10 (1. vydání) [International Classification of Diseases - 10th Revision, ICD-10 (1st Edition)]. Praha: Maxdorf; 1996. Czech.

69. Ritsner M, Kurs R, Gibel A, Ratner Y, Endicott J. Validity of an abbreviated Quality of Life Enjoyment and Satisfaction Questionnaire (Q-LES-Q-18) for schizophrenia, schizoaffective, and mood disorder patients. Qual Life Res. 2005;14(7):1693-1703.

70. Müllerova H, Libigerova E, Prouzova M, et al. Mezikulturní přenos a validace dotazníku kvality života q-les-q (Quality of Life Enjoyment and Satisfaction Questionnaire) v populaci nemocných s depresivní poruchou [Cross-cultural transfer and validation of the Quality of Life Enjoyment and Satisfaction Questionnaire in the population of depressed patients]. Psychiatrie. 2001;5:80-87. Czech.

71. Carlson EB, Putnam FW. An update on the Dissociative Experience Scale. Dissociation. 1993;6(1):16-27.

72. Carlson EB, Putnam FW, Ross CA, et al. Factor analysis of the Dissociative Experiences Scale: a multicenter study. In: Braun BG, Carlson EB, editors. Proceedings of the Eighth International Conference on Multiple Personality and Dissociative States. Chicago, IL: Rush; 1991.

73. Ptacek R, Bob P, Paclt I, et al. Psychobiology of dissociation and its clinical assessment. Neuro Endocrinol Lett. 2007;28(2):191-198.

74. Waller NG, Putnam FW, Carlson EB. Types of dissociation and dissociative types: a taxometric analysis of dissociative experiences. Psychol Methods. 1996;1(3):300-321.

75. Modestin J, Erni T. Testing the dissociative taxon. Psychiatry Res. 2004; 126(1):77-82.

76. Waller NG, Ross CA. The prevalence and biometric structure of pathologic dissociation in the general population: taxometric and behavior genetic findings. J Abnorm Psychol. 1996;106(4):499-510.

77. Ptacek R, Bob P, Paclt I. Skala disociativnich zkusenosti - Ceska verze [Dissociative Experiences Scale - the Czech version]. Cesk Psychol. 2006;50(3):262-272. Czech.

78. Beck AT, Steer RA, Ball R, Ranieri W. Comparison of Beck Depression Inventories-I and -II in psychiatric outpatients. J Pers Assess. 1996;67(3): 588-597.

79. Storch EA, Roberti JW, Roth DA. Factor structure, concurrent validity, and internal consistency of the Beck Depression Inventory - Second Edition in a sample of college students. Depress Anxiety. 2004;19(3): 187-189.

80. Preiss M, Vacir K. Beckova sebeposuzovaci skala depresivity pro dospele - BDI-II [Beck Self-Report Depression Scale for Adults BDI-II]. Brno: Psychodiagnostika; 1999. Slovak.

81. Beck AT, Epstein N, Brown G, Steer RA. An inventory for measuring clinical anxiety: psychometric properties. J Consult Clin Psychol. 1988; 56(6):893-897.

82. Kamaradova D, Prasko J, Latalova K, et al. Psychometric properties of the Czech version of the Beck Anxiety Inventory - comparison between diagnostic groups. Neuro Endocrinol Lett. 2016;36(7):706-712.

83. Guy W, editor. ECDEU Assessment Manual for Psychopharmacology. Rockville, MD: DHEW; 1976.

84. Kadouri A, Corruble E, Falissard B. The improved Clinical Global Impression Scale (ICGI): development and validation in depression. BMC Psychiatry. 2007;7:7. 
85. Sheehan DV, Harnett-Sheehan K, Raj BA. The measurement of disability. Int Clin Psychopharmacol. 1996;11(Suppl 3):89-95.

86. Sheehan DV. The Anxiety Disease. New York: Scribner's; 1983.

87. Sheehan DV. The Sheehan Disability Scales. In: The Anxiety Disease and How to Overcome It. Sheehan DV, editor. New York: Charles Scribner and Sons; 1983:151.

88. Sheehan KH, Sheehan DV. Assessing treatment effects in clinical trials with the discan metric of the Sheehan Disability Scale. Int Clin Psychopharmacol. 2008;23(2):70-83.

89. McGlynn TJ, Metcalf HL, editors. Diagnosis and Treatment of Anxiety Disorders: A Physician's Handbook. Washington, DC: American Psychiatric Press, Inc; 1989:98-99.

90. Albus M, Maier W, Shera D, Bech P. Consistencies and discrepancies in self- and observer-rated anxiety scales. A comparison between the self- and observer-rated Marks-Sheehan scales. Eur Arch Psychiatry Clin Neurosci. 1990;240(2):96-102.

91. European Medicines Agency. Guideline for good clinical practice. 2002. Available from: http://www.edctp.org/fileadmin/documents/ EMEA_ICH-GCP_Guidelines_July_2002.pdf. Accessed May 19, 2016.

92. Zimmerman M, Coryell W. DSM-III personality disorder diagnoses in a nonpatient sample. Demographic correlates and comorbidity. Arch Gen Psychiatry. 1989;46(8):682-689.

93. Arens EA, Stopsack M, Spitzer C, et al. Borderline personality disorder in four different age groups: a cross-sectional study of community residents in Germany. J Pers Disord. 2013;27(2):196-207.

94. Perugi G, Angst J, Azorin JM, et al; BRIDGE-II-Mix Study Group. Relationships between mixed features and borderline personality disorder in 2,811 patients with major depressive episode. Acta Psychiatr Scand. Epub 2015 Jun 12.
95. Ociskova M, Sedlackova Z, Prasko J, Latalova K, Kamaradova D Pokud mě cejchujete, běžte s tou terapií někam! Hraniční porucha osobnosti a stigma [If you label me, go with your therapy to hell! Borderline personality disorder and stigma]. Psychiatrie pro praxi. 2014;15(2):62-66. Czech.

96. Cramer V, Torgersen S, Kringlen E. Socio-demographic conditions, subjective somatic health, Axis I disorders and personality disorders in the common population: the relationship to quality of life. J Pers Disord. 2007;21(5):552-567.

97. Mendlowicz MV, Stein MB. Quality of life in individuals with anxiety disorders. Am J Psychiatry. 2000;157(5):669-682.

98. Latalova K, Prasko J, Diveky T, Kamaradova D, Velartova H. Quality of life in patients with bipolar disorder - a comparison with schizophrenic patients and healthy controls. Psychiatr Danub. 2011;23(1):21-26.

99. Brenes GA. Anxiety, depression, and quality of life in primary care patients. Prim Care Companion J Clin Psychiatry. 2007;9(6):437-443.

100. Baranyi A, Leithgöb O, Kreiner B, et al. Relationship between posttraumatic stress disorder, quality of life, social support, and affective and dissociative status in severely injured accident victims 12 months after trauma. Psychosomatics. 2010;51(3):237-247.

101. Warshaw MG, Fierman E, Pratt L, et al. Quality of life and dissociation in anxiety disorder patients with histories of trauma or PTSD. Am J Psychiatry. 1993;150(10):1512-1516.

102. Dickinson LM, deGruy FV 3rd, Dickinson WP, Candib LM. Healthrelated quality of life and symptom profiles of female survivors of sexual abuse. Arch Fam Med. 1999;8(1):35-43.

103. Price J, Cole V, Goodwin GM. Emotional side-effects of selective serotonin reuptake inhibitors: qualitative study. $\mathrm{Br} J$ Psychiatry. 2009;195(3):211-217.
Patient Preference and Adherence

\section{Publish your work in this journal}

Patient Preference and Adherence is an international, peer-reviewed, open access journal that focuses on the growing importance of patient preference and adherence throughout the therapeutic continuum. Patient satisfaction, acceptability, quality of life, compliance, persistence and their role in developing new therapeutic modalities and compounds to optimize

\section{Dovepress}

clinical outcomes for existing disease states are major areas of interest for the journal. This journal has been accepted for indexing on PubMed Central. The manuscript management system is completely online and includes a very quick and fair peer-review system, which is all easy to use. Visit http://www. dovepress.com/testimonials.php to read real quotes from published authors. 